\title{
Transaction
}

\section{Hydrothermal Synthesis of Carbon Nanotube/Nickel Ferrite Nanocomposites}

\author{
Xudong Jin ${ }^{* 1}$, Qing-Qing $\mathrm{Ni}^{* 2,3}$, Yaqin $\mathrm{Fu}^{* 2}$, Li Zhang ${ }^{* 4}$, and Toshiaki Natsuki ${ }^{* 3}$ \\ ${ }^{* 1}$ Interdisciplinary Graduate School of Science and Technology, Shinshu University, Ueda 386-8567, Japan \\ ${ }^{* 2}$ Key Laboratory of Advanced Textile Materials and Manufacturing Technology Ministry of Education, \\ Zhejiang Sci-Tech University, Hangzhou 310018, P.R. China \\ ${ }^{* 3}$ Department of Functional Machinery and Mechanics, Shinshu University, Ueda 386-8567, Japan \\ ${ }^{* 4}$ Faculty of Engineering, Shinshu University, Japan
}

\begin{abstract}
We report a simple hydrothermal synthesis of carbon nanotube/nickel ferrite $\left(\mathrm{CNT} / \mathrm{NiFe}_{2} \mathrm{O}_{4}\right)$ nanocomposites. The CNTs used in this work were pretreated with nitric acid. The evolution of the synthesis of the CNT/NiFe $\mathrm{O}_{4}$ nanocomposites was studied using X-ray photoelectron spectroscopy, X-ray diffraction, energy-dispersive X-ray spectroscopy, and transmission electron microscopy. The results suggest that $\mathrm{NiFe}_{2} \mathrm{O}_{4}$ nanoparticles were synthesized in situ on the CNT surface. Vibrating-sample magnetometer measurements showed that the $\mathrm{CNT} / \mathrm{NiFe}_{2} \mathrm{O}_{4}$ nanocomposites exhibit typical soft ferromagnetic behavior with saturation magnetization (Ms) of about $24 \mathrm{emu} / \mathrm{g}$.
\end{abstract}

(Received 25 November, 2011; Accepted 6 January, 2012)

\section{Introduction}

Nickel ferrite $\left(\mathrm{NiFe}_{2} \mathrm{O}_{4}\right)$ is an important spinel ferrite nanocrystal, and it has been extensively investigated because of its high electrical resistivity, electromagnetic performance, chemical stability, and moderate saturation magnetization (Ms) [1-3]. $\mathrm{NiFe}_{2} \mathrm{O}_{4}$ nanoparticles have been successfully prepared by a variety of methods such as hydrothermal synthesis [4-7], coprecipitation [8,9], solgel methods [10-12], combustion [13], and shock wave methods [14]. Recently, $\mathrm{NiFe}_{2} \mathrm{O}_{4}$-based magnetic nanocomposites have attracted increasing interest because of their unique properties and potential applications. Much effort has been devoted to this area, and the developed nanocomposites have a wide range of applications, including DNA separation [15], antimicrobial agents [16-19], microwave absorbers [20, 21], and photocatalysts [22-24].

Carbon nanotubes (CNTs) are considered to be suitable candidates for nanocomposite synthesis because of their nanoscale dimensions and excellent properties. Wu et al. [25] synthesized multiwalled CNT/cobalt ferrite magnetic hybrids for drug delivery. A novel glucose biosensor composed of magnetic nanoparticles $\left(\mathrm{Fe}_{3} \mathrm{O}_{4} @\right.$ $\mathrm{SiO}_{2}$ ) and CNTs has been developed by Baby et al. [26]. Deng et al. [27] reported CNTs functionalized with magnetic silica nanoparticles; these CNTs efficiently separate trace aromatic compounds.

The assembly of $\mathrm{NiFe}_{2} \mathrm{O}_{4}$ nanoparticles on CNTs is therefore a feasible and interesting method of synthesizing magnetic nanocomposites. However, to our knowledge, there have been few reports of $\mathrm{CNT} / \mathrm{NiFe}_{2} \mathrm{O}_{4}$ nanocomposites. In this work, we synthesized $\mathrm{CNT} / \mathrm{NiFe}_{2} \mathrm{O}_{4}$ nanocomposites in situ using a simple hydrothermal method, and studied the process involved in $\mathrm{CNT} / \mathrm{NiFe}_{2} \mathrm{O}_{4}$ synthesis.

\section{Experimental}

All reagents were analytical grade and used as received. Multiwalled CNTs of diameter 20-30 nm were purchased from Wako Pure Chemical Industries Ltd., Osaka, Japan.

Pristine CNTs $(30 \mathrm{mg}$ ) were added to $60 \mathrm{~mL}$ of $10 \mathrm{M}$ nitric acid and dispersed ultrasonically for $1 \mathrm{~h}$. The CNT suspension was then transferred to a roundbottomed flask equipped with a reflux condenser, and refluxed with constant stirring at $130{ }^{\circ} \mathrm{C}$ for $12 \mathrm{~h}$. The obtained CNTs were collected and washed repeatedly with distilled water to remove residual nitric acid and impurities.

A typical synthetic process is as follows. First, $11 \mathrm{mg}$ of treated CNTs were completely dispersed in $50 \mathrm{~mL}$ of distilled water by ultrasonication for $1 \mathrm{~h}$. Then $0.1 \mathrm{mmol}$ of $\mathrm{Fe}\left(\mathrm{NO}_{3}\right)_{3} \cdot 9 \mathrm{H}_{2} \mathrm{O}$ and $0.05 \mathrm{mmol}$ of $\mathrm{Ni}\left(\mathrm{NO}_{3}\right)_{2} \cdot 6 \mathrm{H}_{2} \mathrm{O}$ were dissolved in the CNT suspension. Sodium hydroxide solution was added dropwise, with vigorous stirring, to adjust the $\mathrm{pH}$ value to about 12.5 . 
(The intermediate product formed during precipitation is referred to as $\mathrm{CNT} / \mathrm{NiFeOH}$.) The obtained mixture was transferred to a PTFE-lined stainless-steel autoclave, and the hydrothermal reaction was conducted at $170{ }^{\circ} \mathrm{C}$ for $12 \mathrm{~h}$. After cooling to room temperature, the as-prepared products were separated by filtration and washed several times with distilled water and ethanol.

The morphologies of the products were examined using transmission electron microscopy (TEM; JEM2010, JEOL, Tokyo, Japan) with an accelerating voltage of $200 \mathrm{kV}$. X-ray diffraction (XRD) patterns were recorded using a Rigaku Geigerflex 2028 diffractometer (Rigaku, Tokyo, Japan) with $\mathrm{Cu} \mathrm{K} \alpha$ radiation (1.5406 ̊). Energy-dispersive X-ray (EDX) spectroscopy was performed using an instrument attached to a scanning electron microscope (S-3400N, Hitachi, Tokyo, Japan). X-ray photoelectron spectroscopy (XPS) was performed using an AXIS-ULTRA DLD (Kratos, Hadano, Japan) spectrometer with a standard $\mathrm{Mg} \mathrm{K \alpha}(1256.6 \mathrm{eV}) \mathrm{X}$-ray source $(10 \mathrm{~mA}$ and $15 \mathrm{kV})$, and the binding energies were referenced to $\mathrm{C} 1 \mathrm{~s}$ at $284.3 \mathrm{eV}$. Magnetic properties were determined using a vibrating-sample magnetometer (VSM) over an applied magnetic field with a maximum strength of $\pm 10 \mathrm{kOe}$ at room temperature.

\section{Results and discussion}

Multiwalled CNTs can be considered to be "rolledup" sheets of graphite [28]. The structure of CNTs gives them some excellent properties, but it also leads to poor solubility and chemical inertness, and these significantly limit further extension of CNT applications. In this work, to overcome these limitations, concentrated aqueous nitric acid was used to functionalize the CNTs.

XPS measurements were performed to determine the elemental composition at the CNT surface; the survey scan spectra are presented in Fig. 1(a). In the spectrum of the treated CNTs, in addition to the intense C1s peak, an O1s peak, significantly more intense than the corresponding peak in the spectrum of the pristine CNTs, is observed. This could be attributed to the presence of oxygen-containing functional groups on the CNT surface after oxidative treatment. The high-resolution spectra for $\mathrm{C} 1 \mathrm{~s}$ from pristine and treated CNTs are presented in Fig. 1(b). It can be observed that the shoulder of the spectrum of the treated CNTs is higher than that of the pristine CNTs. Furthermore, the C1s peaks from pristine and treated CNTs were fitted by a superposition of five peaks, giving a detailed description of the oxidation states of the carbons. As well as the peaks corresponding to
-C-C- $\left(\mathrm{sp}^{2}, \mathrm{sp}^{3}\right)$ at $284.3 \mathrm{eV}$ and $284.7 \mathrm{eV}$, there were three other peaks, which could be indexed to -C-O- $(286.2 \mathrm{eV})$, $-\mathrm{C}=\mathrm{O}(287.5 \mathrm{eV})$, and $-\mathrm{COO}-(289.2 \mathrm{eV})$. According to the peak areas from treated CNT, the percentages of the corresponding functional groups were as follows : -C-O-, $5.7 \%$; $-\mathrm{C}=\mathrm{O}, 4.4 \%$; and $-\mathrm{COO}-10.4 \%$. The XPS results therefore indicated that oxygen-containing functional groups were introduced on the surface of pristine CNTs through the nitric acid treatment; this agrees with previously reported results [29].

The oxidative treatment is considered to play a critical role in the whole synthetic process. The created oxygen-containing functional groups improve the hydrophilicity of the CNTs, enabling them to be well dispersed in water, which could favor uniform distribution of synthesized nanoparticles on the CNTs.
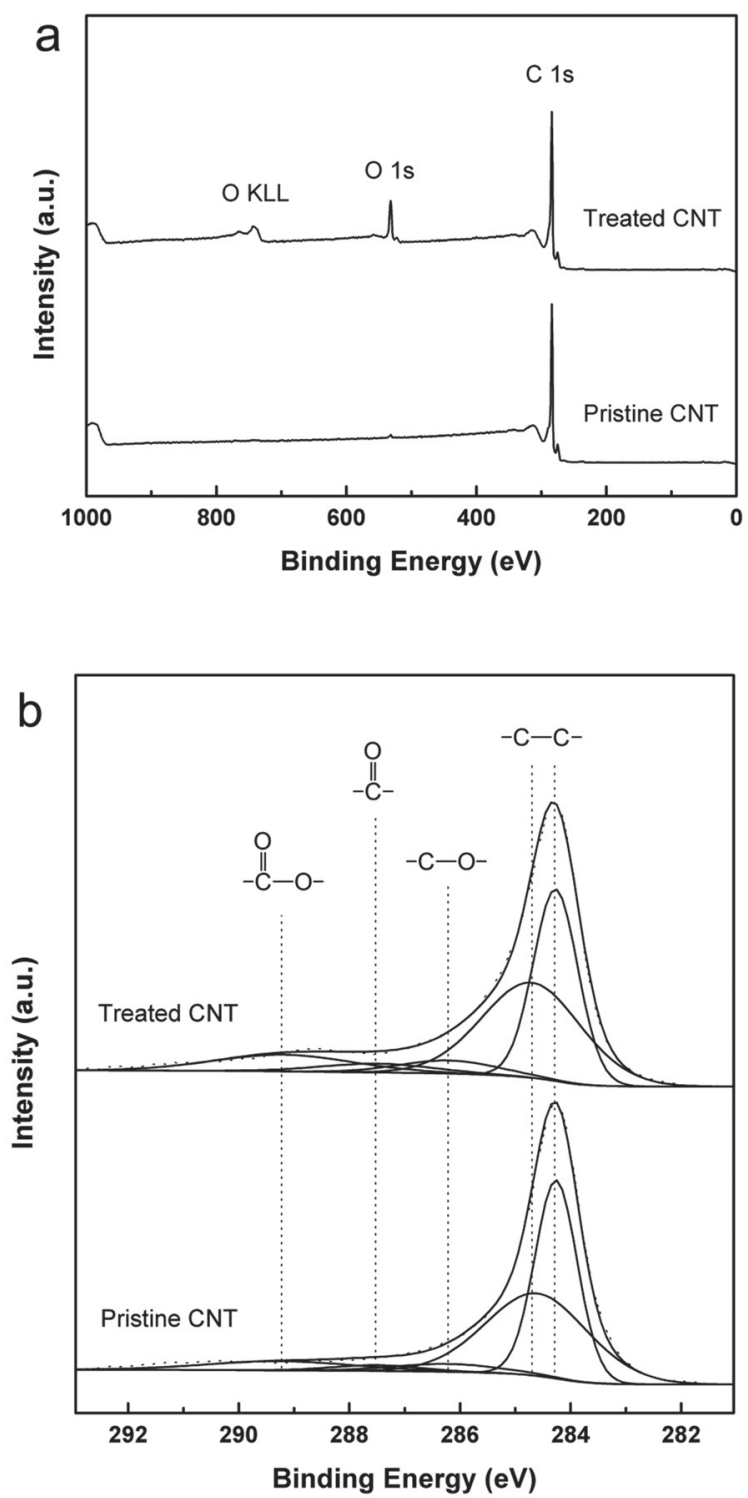

Fig. 1 XPS spectra of CNTs before and after treatment with nitric acid: (a) wide-scan spectra and (b) high-resolution spectra for $\mathrm{C} 1 \mathrm{~s}$. 


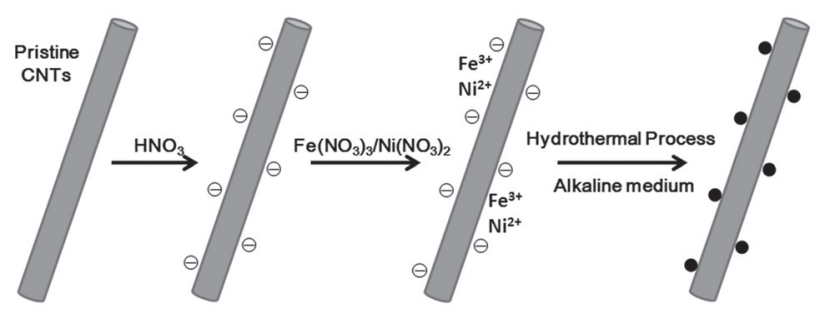

Fig. 2 Schematic diagram of the proposed process for $\mathrm{CNT} / \mathrm{NiFe}_{2} \mathrm{O}_{4}$ synthesis.

These functional groups could also adsorb metal ions in solution $[30,31]$ by electrostatic interactions. The synthesis of $\mathrm{CNT} / \mathrm{NiFe}_{2} \mathrm{O}_{4}$ could therefore involve the following three steps, shown in Fig. 2.

First, as mentioned above, pristine CNTs were oxidized by nitric acid, and functional groups (carbonyl, carboxyl, and hydroxy) were introduced. Secondly, the $\mathrm{Fe}^{3+}$ and $\mathrm{Ni}^{2+}$ in the solution were self-adsorbed on the CNT surface, where the functional groups were grafted. In step 3, $\mathrm{NiFe}_{2} \mathrm{O}_{4}$ nanoparticles were hydrothermally synthesized in situ on the CNT surface in an alkaline medium; the reaction is as follows :

$$
\mathrm{Ni}\left(\mathrm{NO}_{3}\right)_{2}+2 \mathrm{Fe}\left(\mathrm{NO}_{3}\right)_{3}+8 \mathrm{NaOH} \rightarrow \mathrm{NiFe}_{2} \mathrm{O}_{4}+8 \mathrm{NaNO}_{3}+4 \mathrm{H}_{2} \mathrm{O}
$$

Corresponding to this process (Fig. 2), TEM images of the CNTs before and after hydrothermal synthesis are presented in Fig. 3. The image in Fig. 3(a) shows welldistributed oxidized CNTs; the good distribution could be attributed to improved hydrophilicity. Although oxidative treatments always induce significant etching of CNTs, no obvious fractures or shortening phenomena are observed in Fig. 3(a). The image of $\mathrm{CNT} / \mathrm{NiFe}_{2} \mathrm{O}_{4}$ sample hydrothermally synthesized at $170{ }^{\circ} \mathrm{C}$ is shown in Fig. 3(b). Many nanoscale particles are observed supported on the surface of the CNTs. This indicates that the $\mathrm{CNT} / \mathrm{NiFe}_{2} \mathrm{O}_{4}$ nanocomposites were successfully synthesized at $170{ }^{\circ} \mathrm{C}$. The loading of $\mathrm{NiFe}_{2} \mathrm{O}_{4}$ nanoparticles on CNT was measured by removing CNT at a high temperature, and the result showed a weight percentage $\left(\mathrm{NiFe}_{2} \mathrm{O}_{4}: \mathrm{CNT} / \mathrm{NiFe}_{2} \mathrm{O}_{4}\right)$ of 50.6 wt.\%, which approximately agrees with the value calculated based on initial amount of the CNTs and metallic salts.

The XRD patterns were used to determine the evolution of the crystal structures of the $\mathrm{CNT} / \mathrm{NiFe}_{2} \mathrm{O}_{4}$ nanocomposites. For the intermediate product CNT/ $\mathrm{NiFeOH}$, as shown in Fig. 4(a), except for the peak at around $\theta=26^{\circ}$, no diffraction peaks are observed; the peak at $\theta=26^{\circ}$ could be assigned to the (002) planes of the CNTs, corresponding to the stacked graphene layers of the CNTs. The results show that an $\mathrm{NiFe}_{2} \mathrm{O}_{4}$ crystal
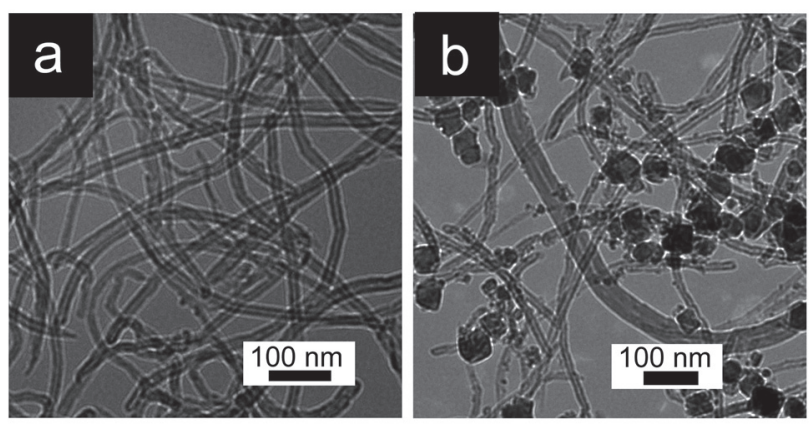

Fig. 3 TEM images of (a) treated CNTs, (b) CNT/ $\mathrm{NiFe}_{2} \mathrm{O}_{4}$ synthesized at $170{ }^{\circ} \mathrm{C}$.
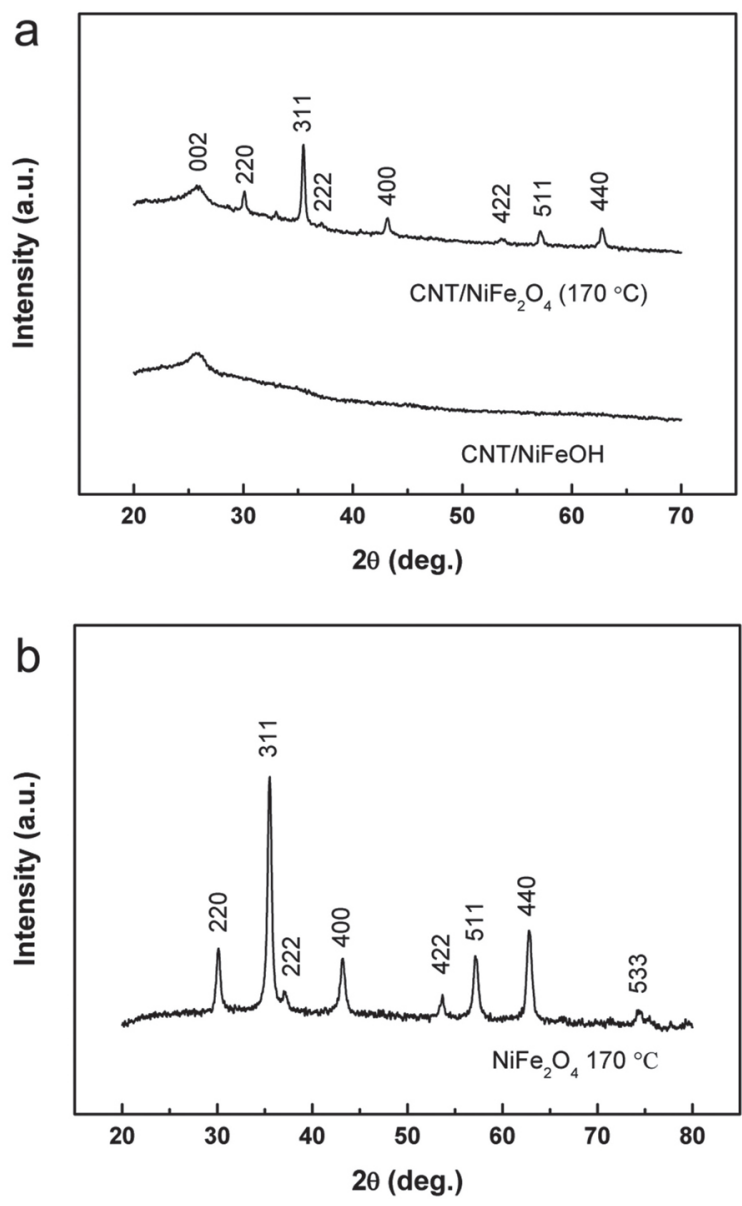

Fig. 4 XRD patterns of (a) $\mathrm{CNT} / \mathrm{NiFe}_{2} \mathrm{O}_{4}$ and $\mathrm{CNT} /$ $\mathrm{NiFeOH}$ and (b) $\mathrm{NiFe}_{2} \mathrm{O}_{4}$.

structure was not formed when the metal ions were precipitated, before the hydrothermal reaction. However, for the sample hydrothermally synthesized at $170{ }^{\circ} \mathrm{C}$, as well as the peak at around $\theta=26^{\circ}$, the pattern also shows several other obvious diffraction peaks that could be indexed to the (220), (311), (222), (400), (422), (511), and (440) crystal planes, matching the spinel structure of $\mathrm{NiFe}_{2} \mathrm{O}_{4}$ (JCPDS 54-0964) well. This confirmed that the $\mathrm{CNT} / \mathrm{NiFe}_{2} \mathrm{O}_{4}$ nanocomposites were successfully produced. Moreover, Fig. 4(a) illustrates that the $\mathrm{NiFe}_{2} \mathrm{O}_{4}$ crystal structure was formed during the hydrothermal 
process.

We also see a small diffraction peak between the (220) and (311) planes. This peak is believed to correspond to the $\mathrm{Fe}_{2} \mathrm{O}_{3}$ phase $[32,33]$, which means that there is a small amount of $\mathrm{Fe}_{2} \mathrm{O}_{3}$ impurities in the CNT/ $\mathrm{NiFe}_{2} \mathrm{O}_{4}$ nanocomposites. As a reference, pure $\mathrm{NiFe}_{2} \mathrm{O}_{4}$ nanoparticles were synthesized under the same conditions, and the XRD pattern is shown in Fig. 4(b). For the $\mathrm{NiFe}_{2} \mathrm{O}_{4}$ synthesized at $170{ }^{\circ} \mathrm{C}$, the diffraction peaks match the standard spinel structure of $\mathrm{NiFe}_{2} \mathrm{O}_{4}$ well, and no other impurity peaks are observed.

It could therefore be concluded that the CNTs interfered with the synthesis of $\mathrm{NiFe}_{2} \mathrm{O}_{4}$. We think that the adsorption of metal ions on the CNTs hinders free movement of these ions; this means that the synthesis cannot completely follow the initial stoichiometric ratios of the metal ions, which were added in a molar ratio of 2 : $1\left(\mathrm{Fe}^{3+}: \mathrm{Ni}^{2+}\right)$.

EDX spectrometry was used to further analyze the chemical compositions of the product, and a typical EDX spectrum of a CNT/NiFe $\mathrm{O}_{4}$ nanocomposite is shown in Fig. 5. Ni, Fe, and $\mathrm{C}$ were obviously detected. A few small peaks corresponding to $\mathrm{Si}$ and $\mathrm{Ca}$ were also observed in the spectrum; these impurities could be imported from the glass tube used for holding the CNT/ $\mathrm{NiFe}_{2} \mathrm{O}_{4}$ sample ; hence we could still consider that the as -prepared $\mathrm{CNT} / \mathrm{NiFe}_{2} \mathrm{O}_{4}$ sample contained only the desired elements ( $\mathrm{Ni}, \mathrm{Fe}$, and $\mathrm{C}$ ), and no other impurities. The strong $\mathrm{C}$ peak in the spectrum could be attributed to the CNTs. In addition, the atomic ratio of $\mathrm{Fe}$ to $\mathrm{Ni}$ (as shown in the inset) is 2.07 , which is very close to the stoichiometric composition of $\mathrm{NiFe}_{2} \mathrm{O}_{4}$.

The XPS spectra shown in Fig. 6 were used to further investigate the evolution of the CNT surface. The

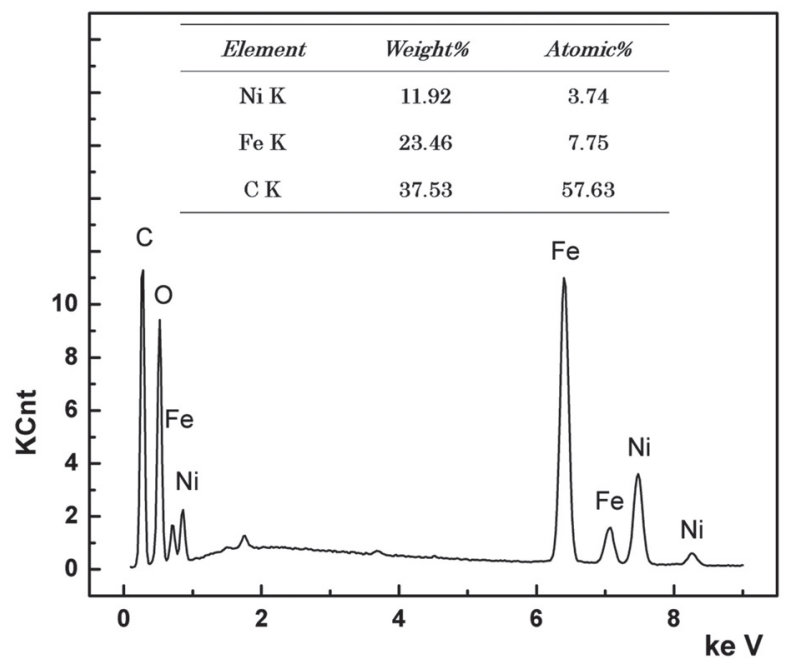

Fig. 5 EDX pattern for $\mathrm{CNT} / \mathrm{NiFe}_{2} \mathrm{O}_{4}$. wide-scan spectra of treated CNTs and $\mathrm{CNT} / \mathrm{NiFe}_{2} \mathrm{O}_{4}$ are shown in Fig. 6(a). In addition to the strong peaks corresponding to $\mathrm{O} 1 \mathrm{~s}$ and $\mathrm{C} 1 \mathrm{~s}$ (seen in Fig. 1), peaks assigned to $\mathrm{Ni} 2 \mathrm{p}$ and $\mathrm{Fe} 2 \mathrm{p}$ are also clearly observed in the spectrum of $\mathrm{CNT} / \mathrm{NiFe}_{2} \mathrm{O}_{4}$. This indicates that $\mathrm{Fe}$ and $\mathrm{Ni}$ are present on the CNT surface of the sample obtained by hydrothermal synthesis, and it also agrees with the EDX results (Fig. 5).

As shown in Fig. 6(b), the high-resolution spectra of $\mathrm{Ni} 2 \mathrm{p}$ provide further detailed descriptions of the
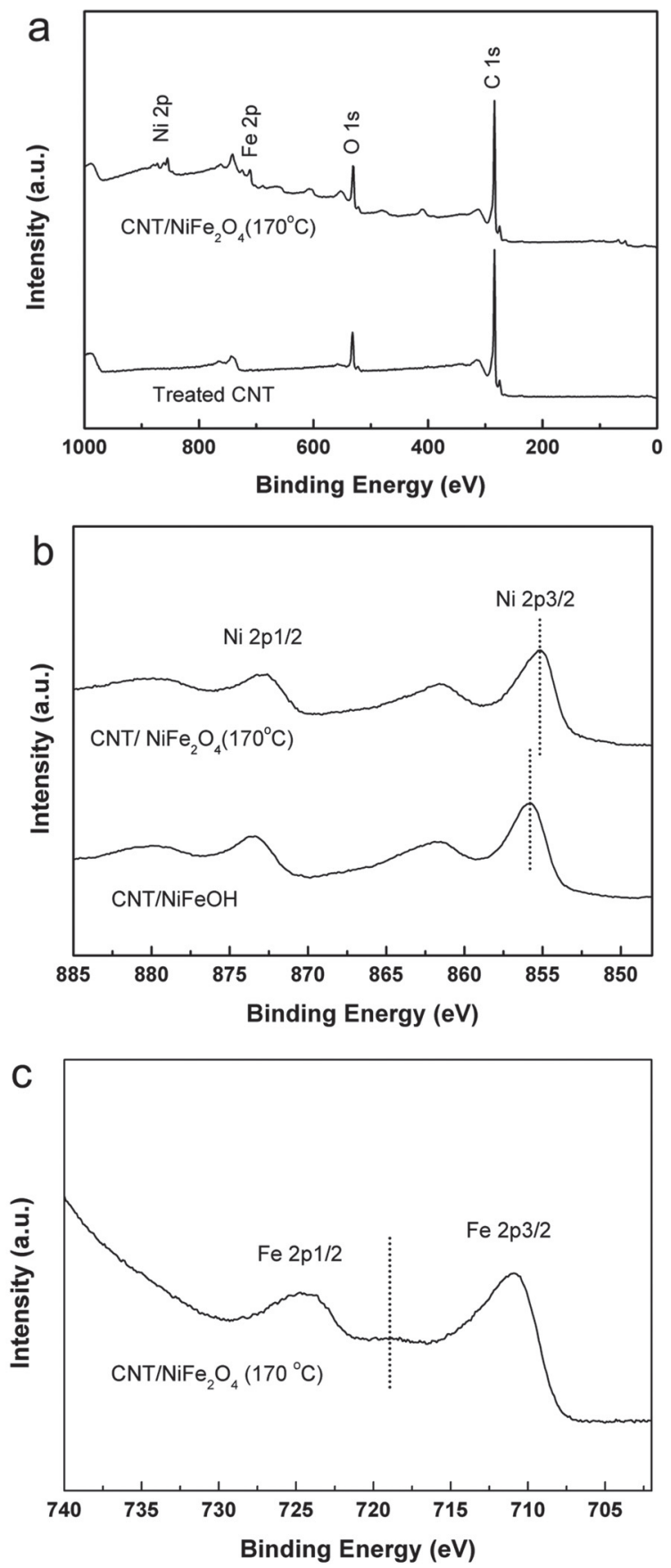

Fig. 6 (a) XPS wide-scan spectra of $\mathrm{CNT} / \mathrm{NiFe}_{2} \mathrm{O}_{4}$ and treated CNTs ; (b) high-resolution Ni2p spectra of $\mathrm{CNT} / \mathrm{NiFe}_{2} \mathrm{O}_{4}$ and $\mathrm{CNT} / \mathrm{NiFeOH}$; and (c) high-resolution $\mathrm{Fe} 2 \mathrm{p}$ spectrum of $\mathrm{CNT} / \mathrm{NiFe}_{2} \mathrm{O}_{4}$. 
evolution before and after hydrothermal synthesis. For $\mathrm{CNT} / \mathrm{NiFeOH}$, the main peak, assigned to $\mathrm{Ni} 2 \mathrm{p} 3 / 2$, appeared at $855.8 \mathrm{eV}$, accompanied by a satellite at $861.9 \mathrm{eV}$; it was speculated that $\mathrm{Ni}(\mathrm{OH})_{2}$ was formed on the CNT surface. [34] Compared with $\mathrm{CNT} / \mathrm{NiFeOH}$, there is a slight shift of $\mathrm{Ni} 2 \mathrm{p}$ for $\mathrm{CNT} / \mathrm{NiFe}_{2} \mathrm{O}_{4}$, and the peak assigned to Ni2p is located at $855.2 \mathrm{eV}$. [35] This shift could be attributed to the influence of $\mathrm{NiFe}_{2} \mathrm{O}_{4}$ formation after hydrothermal synthesis. The presence of $\mathrm{Ni}$ on the CNT surface for $\mathrm{CNT} / \mathrm{NiFeOH}$, even after washing several times, also supported the suggestion that $\mathrm{Ni}^{2+}$ was adsorbed on the CNT surface.

The formation of $\mathrm{NiFe}_{2} \mathrm{O}_{4}$ was also proved by the $\mathrm{Fe}$ $2 p$ spectrum, as shown in Fig. 6(c). The high-resolution spectrum shows an Fe2p3/2 peak at $711 \mathrm{eV}$. This result is consistent with others reported in the literature $[35,36]$. As indicated by a dotted line in Fig. 6(c), a small satellite peak appearing at about $8 \mathrm{eV}$ above the main Fe2p3/2 peak suggested the presence of $\mathrm{Fe}^{3+}$ in $\mathrm{CNT} / \mathrm{NiFe}_{2} \mathrm{O}_{4}[36$, 37].

The magnetic properties of the as-prepared CNT/ $\mathrm{NiFe}_{2} \mathrm{O}_{4}$ nanocomposites were determined by VSM at room temperature, and the field-dependent magnetization of as-prepared $\mathrm{CNT} / \mathrm{NiFe}_{2} \mathrm{O}_{4}$ nanocomposites was obtained with a maximum applied field up to $10 \mathrm{kOe}$. The corresponding curve is presented in Fig. 7, and the typical hysteresis loop indicates soft ferromagnetic behavior. It is observed that the $\mathrm{CNT} / \mathrm{NiFe}_{2} \mathrm{O}_{4}$ nanocomposites synthesized at $170{ }^{\circ} \mathrm{C}$ exhibit a saturation magnetization (Ms) of about $24 \mathrm{emu} / \mathrm{g}$. The results of the magnetic measurements therefore suggested that $\mathrm{CNT} / \mathrm{NiFe}_{2} \mathrm{O}_{4}$ nanocomposites with soft ferromagnetic behavior were obtained in this work.

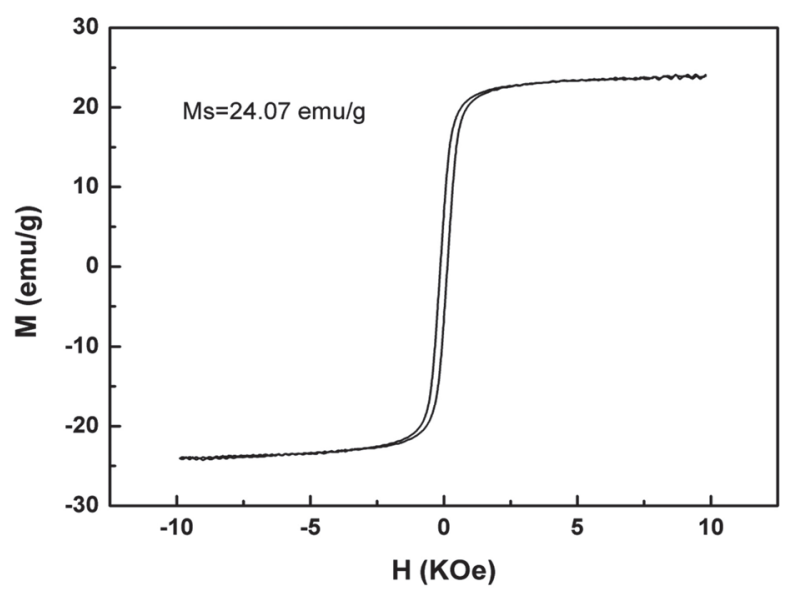

Fig. 7 Magnetization curve of $\mathrm{CNT} / \mathrm{NiFe}_{2} \mathrm{O}_{4}$ at room temperature.

\section{Conclusion}

In this work, $\mathrm{CNT} / \mathrm{NiFe}_{2} \mathrm{O}_{4}$ nanocomposites were synthesized using a simple hydrothermal method. A process for the synthesis of $\mathrm{CNT} / \mathrm{NiFe}_{2} \mathrm{O}_{4}$ nanocomposites was proposed and confirmed by characterization using XPS, XRD, and EDX. The results suggested that $\mathrm{NiFe}_{2} \mathrm{O}_{4}$ was synthesized in situ on the CNT surface. The TEM image showed $\mathrm{NiFe}_{2} \mathrm{O}_{4}$ nanoparticles supported on the CNTs. Magnetic measurements illustrated that the CNT/ $\mathrm{NiFe}_{2} \mathrm{O}_{4}$ nanocomposites are typical soft ferromagnetic materials with an Ms of about $24 \mathrm{emu} / \mathrm{g}$.

\section{Acknowledgment}

This work was supported by a Grant-in-Aid Global COE Program from the Ministry of Education, Culture, Sports, Science and Technology, Japan.

\section{References}

1. M. G. Naseri, E. B. Saion, H. A. Ahangar, M. Hashim, and A. H. Shaari, Powder Technol., 212, 80 (2011).

2. X. Cao, J. Meng, F. Mi, Z. Zhang, and J. Sun, Solid State Commun., 151, 678 (2011).

3. Z. Wang, X. Liu, M. Lv, P. Chai, Y. Liu, and J. Meng, J. Phys. Chem. B, 112, 11292 (2008).

4. J. Zhou, J. Ma, C. Sun, L. Xie, Z. Zhao, and H. Tian, J. Am. Ceram. Soc., 88, 3535 (2005).

5. J. Wang, Mater. Sci. Eng. B, 127, 81 (2006).

6. J. Zhang, J. Shi, and M. Gong, J. Solid State Chem., 182, 2135 (2009).

7. S. Komarneni, J. Am. Ceram. Soc., 81, 3041 (1998).

8. Y. Shi, J. Ding, X. Liu, and J. Wang, J. Magn. Magn. Mater., 205, 249 (1999).

9. K. Maaz, S. Karim, A. Mumtaz, S. K. Hasanain, J. Liu, and J. L. Duan, J. Magn. Magn. Mater., 321, 1838 (2009).

10. P. Lavela, and J. L. Tirado, J. Power Sources, 172, 379 (2007).

11. M. George, A. M. John, S. S. Nair, P. A. Joy, and M. R. Anantharaman, J. Magn. Magn. Mater., 302, 190 (2006).

12. D. Chen, and X. He, Mater. Res. Bull., 36, 1369 (2001)

13. T. Prabhakaran, and J. Hemalatha, J. Alloys Compd., 509, 7071 (2011).

14. J. Liu, H. He, X. Jin, Z. Hao, and Z. Hu, Mater. Res. Bull., 36, 2357 (2001). 
15. J. Nam, Y. Joo, J. Lee, J. H. Chang, J. H. Cho, M. P. Chun, and B. I. Kim, J. Magn. Magn. Mater., 321, 1389 (2009).

16. B. K. Sunkara, and R. D. K. Misra, Acta Biomater., 4, 273 (2008).

17. S. Rana, J. Rawat, M. M. Sorensson, and R. D. K. Misra, Acta Biomater. , 2, 421 (2006).

18. J. Rawat, S. Rana, R. Srivastava, and R. D. K. Misra, Mater. Sci. Eng. C, 27, 540 (2007).

19. S. Li, E. Wang, C. Tian, B. Mao, Z. Kang, Q. Li, and G. Sun, J. Solid State Chem., 181, 1650 (2008).

20. V. Sunny, P. Kurian, P. Mohanan, P. A. Joy, and M. R. Anantharaman, J. Alloys Compd., 489, 297 (2010).

21. S. Tyagi, H. B. Baskey, R. C. Agarwala, V. Agarwala, and T. C. Shami, Ceram. Int., 37, 2631 (2011).

22. P. P. Hankare, R. P. Patil, A. V. Jadhav, K. M. Garadkar, and R. Sasikala, Appl. Catal. B, 107, 333 (2011).

23. Y. Li, X. Dong, and J. Li, Particuology, 9, 475 (2011).

24. S. Xu, W. Shangguan, J. Yuan, M. Chen, and J. Shi, Appl. Catal. B, 71, 177 (2007).

25. H. Wu, G. Liu, X. Wang, J. Zhang, Y. Chen, J. Shi, H. Yang, H. Hu, and S. Yang, Acta Biomater., 7, 3496 (2011).
26. T. T. Baby, and S. Ramaprabhu, Talanta, 80, 2016 (2010).

27. Y. Deng, C. Deng, D. Yang, C. Wang, S. Fu, and X. Zhang, Chem. Commun., 5548 (2005).

28. E. T. Thostenson, Z. Ren, and T. Chou, Compos. Sci. Technol., 61, 1899 (2001).

29. K. A. Wepasnick, B. A. Smith, K. E. Schrote, H. K. Wilson, S. R. Diegelmann, and D. H. Fairbrother, CARBON, 49, 24 (2011).

30. K. Pyrzynska, Trends Anal. Chem., 29, 718 (2010).

31. Q. Zhang, M. Zhu, Q. Zhang, Y. Li, and H. Wang, Mater. Chem. Phys., 116, 658 (2009).

32. V. Šepelák, I. Bergmann, A. Feldhoff, P. Heitjans, F. Krumeich, D. Menzel, F. J. Litterst, S. J. Campbell, and K. D. Becker, J. Phys. Chem. C, 111, 5026 (2007).

33. Y. Cheng, Y. Zheng, Y. Wang, F. Bao, and Y. Qin, J. Solid State Chem., 178, 2394 (2005).

34. S. Mu, D. Wu, Y. Wang, Z. Wu, X. Yang, and W. Yang, ACS Appl. Mat. Interfaces, 1, 111 (2010).

35. V. K. Mittal, P. Chandramohan, S. Bera, M. P. Srinivasan, S. Velmurugan, and S. V. Narasimhan, Solid State Commun., 137, 6 (2006).

36. A. B. Nawale, N. S. Kanhe, K. R. Patil, S. V. Bhoraskar, V. L. Mathe, and A. K. Das, J. Alloys Compd., 509, 4404 (2011).

37. J. Haetge, C. Suchomski, and T. Brezesinski, Inorg. Chem., 49, 11619 (2010). 